\title{
3 Boyutlu Yazıcı ile Farklı Yazdırma Parametreleri Kullanılarak Üretilen Ĕgme Test Numunelerinin Mekanik Özelliklerinin İncelenmesi
}

\author{
Muhammed Safa KAMER ${ }^{* 1}$, Oğuz DOĞAN ${ }^{1}$, Şemsettin TEMIZZ ${ }^{2}$, \\ Hakan YAYKAŞLI ${ }^{3}$ \\ ${ }^{1}$ Kahramanmaraş Sütçü Imam Üniversitesi, Makine Mühendisliği Bölümü, \\ Kahramanmaraş \\ ${ }^{2}$ Inönü Üniversitesi, Makine Mühendisliği Bölümü, Malatya \\ ${ }^{3}$ Kahramanmaraș İstiklal Üniversitesi, Elbistan Meslek Yüksekokulu, Kahramanmaraş
}

Geliş tarihi: 25.06.2021 Kabul tarihi: 13.09.2021

$\ddot{O} z$

Eklemeli imalat yöntemi ile üretilen parçaların mekanik özelliklerinin bilinmesi tasarımcılar ve kullanıcılar için büyük önem teşkil etmektedir. Bu çalışmada, eklemeli imalat yöntemine ait, üretim parametrelerinden nozul sıcaklığı, tabla sıcaklığı ve dolgu deseni değişiminin, eğilmeye karşı olan etkisi deneysel olarak araştırılmıştır. ABS ve PLA malzemeler kullanılarak farklı üretim parametrelerine sahip deney numuneleri üç boyutlu yazıcılar ile üretilmiştir. Üretilen numuneler üç noktalı eğme testine tabi tutulmuştur. Deneyler sonucunda her bir parametrenin etkisinin gözlemlenmesi için kuvvet-sehim eğrileri oluşturulmuş ve sonuçlar değerlendirilmiştir. Sonuç olarak PLA malzemesinin eğilme dayanımının ABS malzemeye göre daha yüksek oldu tespit edilmiştir. Ayrıca PLA malzemesi için nozul sıcaklığının düşmesi ile eğilme dayanımının da büyük oranda düştüğü tespit edilmiştir. Dolgu deseni değişiminin, hem ABS hem de PLA malzemesi için eğilme dayanımını kayda değer oranda değiştirdiği gözlemlenmiştir.

Anahtar Kelimeler: Eklemeli imalat, Erimiş yığma modellemesi (EYM), 3B Yazıcı, Eğme testi, Dolgu deseni, Nozul ve tabla sicaklı̆̆ı

\section{Investigation of the Mechanical Properties of Flexural Test Samples Produced Using Different Printing Parameters with a 3D Printer}

\begin{abstract}
Definition of the mechanical properties of the parts produced by the additive manufacturing method is of great importance for designers and users. In this study, the effects of the production parameters of the additive manufacturing method, such as nozzle, table temperature, and the variation of the filling pattern
\end{abstract}

"Sorumlu yazar (Corresponding Author): Muhammed Safa KAMER, msafakamer@ksu.edu.tr 
on flexural strength, are experimentally investigated. The test samples with different production parameters using ABS and PLA materials are produced with 3D printers. The produced samples are subjected to the three-point flexural test. As a result of the experiments, force-deflection curves are created. The effects of each parameter, and the results are evaluated. It has been determined that PLA is generally more durable in flexural strength than ABS. In addition, it is determined that the change of nozzle temperature for PLA material considerably changed its mechanical properties. The infill pattern change significantly changed the mechanical properties of both PLA and ABS material.

Keywords: Additive manufacturing, Fused deposition modeling (FDM), 3D Printer, Flexural test, Infill pattern, Printing and bed temperature

\section{GíRiș}

Üç boyutlu üretim tekniği, üretilecek parçanın tek parça halinde katman katman işlenerek üretilmesi mantığına dayanan bir üretim metodu olarak karşımıza çıkmaktadır. $\mathrm{Bu}$ üretim tekniğinde hammadde ısıtılarak akışkan hale getirilir ve bir nozuldan geçirilerek üretilecek olan parçanın katmanlar halinde üretilmesi sağlanır. Geliştirilen bu yeni üretim tekniği sayesinde geleneksek üretim yöntemleri ile tek aşamada üretilemeyecek olan ürünler kolaylıkla üretilebilir hale gelmiş ve üç boyutlu üretim tekniği gün geçtikçe pratik yaşamda da önemini arttırmaya başlamıştır. Ngo ve arkadaşları [1] kapsamlı derleme çalışmalarında eklemeli üretimin avantajlarını; tasarım özgürlüğü, kişiselleştirme, atık minimizasyonu, karmaşık yapıları üretme yeteneği olarak sıralamaktadır.

Önemi her geçen gün artan bu teknoloji ile üretilen malzemelerin mekanik özelliklerinin incelenerek belirlenmesi son yıllarda araştırmacılar tarafından büyük ilgi ile karşılanmıştır. Literatür incelendiğinde özellikle son yıllarda, eklemeli imalat yöntemi ile üretilen ürünlerin mekanik özelliklerinin belirlenmesine yönelik birçok farklı çalışmanın olduğu görülmektedir. Popescu ve arkadaşları [2] FDM üretim parametrelerinin polimer test numunelerinin mekanik özelliklerine olan etkilerini derleme çalışmaların kapsamlı olarak özetlemişlerdir. Eklemeli üretim ile üretilen malzemeler için en belirleyici mekanik özelliklerin çekme, basma, eğilme ve darbe dayanımları olduğu vurgulanmaktadır.

Mekanik özellikler özelinde incelediğimiz literatürde en fazla farklı üretim parametrelerinin çekme dayanımı üzerine olan etkisinin incelendiği görülmektedir. Jayanth ve arkadaşları [3] eklemeli imalat yöntemi ile üretilen ABS malzemesi için kimyasal işlemlerin yüzey pürüzlüğü ve çekme dayanımına etkisini deneysel olarak araştırmıştır. Kimyasal işlem sonucunda daha yüzey pürüzlülüğü elde edilmesine karşın, daha kötü çekme mukavemet değerleri elde edilmiştir. Rajpurohit ve arkadaşları [4] tarama açısı, genişliği ve katman yüksekliği yüksekliğinin çekme dayanımına etkisini deneysel olarak incelemiştir. Tarama açısı $0^{\circ}$ olduğunda en yüksek $90^{\circ}$ olduğunda en düşük çekme dayanımları elde edilmiştir. Üç boyutlu yazdırma işleminde bazı malzemelere takviye eklemeleri yapılarak malzemelerin mekanik davranışları incelenmiştir. Bakır ve karbon fiber eklenmiş PLA malzemesinin, eklenmemiş malzemeye göre çekme dayanımlarının düştüğü tespit edilmiştir [5]. Ayrıca bazı çalışmalarda ise, sağ ve sol yarıları farklı renklerde üretilen PLA çekme numunelerinin yapıştırma bağlı ile bağlanarak çekme testine tabi tutulmuş ve yapıştırma dayanımı tespit edilmiştir [6]. Rodríguez-Panes ve arkadaşları [7] PLA ve ABS test numunelerinin mekanik performansı üzerindeki katman yüksekliği, dolgu yoğunluğu ve katman yöneliminin etkisini deneysel olarak karşılaştırmıştır. Tüm parametreler için PLA kullanılarak üretilen test numuneleri daha rijit bir performans sergilemiştir ayrıca ABS'den daha fazla çekme mukavemetine sahip oldukları tespit edilmiştir.

Eklemeli imalat yöntemi ile üretilen polimerlerin darbe dayanımlarının incelenmesine yönelikte literatürde birçok çalışma bulunmaktadır. Tezel ve arkadaşları [8] ABS, PLA, PET-G ve PC malzemeleri için, farklı katman yüksekliği ve 
üretim açılarının darbe dayanımına olan etkisini deneysel olarak incelemiştir. Sood ve arkadaşları [9] FDM metodu ile üretilen test numunelerinin çekme, eğilme ve darbe dayanımları deneysel olarak incelemiştir. Çalışmada, beş farklı tasarım parametresinin etkisi incelenmiştir. Ayrıca deneylerden elde edilen sonuçlar ile ampirik ifadeler elde edilmiş ve varyans analizi yapılarak doğrulanmıştır. Eklemeli imalat yönteminde kontrol edilebilir bir diğer parametre ise dolgu oranı ve deseni olarak karşımıza çıkmaktadır. Liu ve arkadaşları [10] farklı dolgu oranlarının TPE malzemesinden üretilen çekme numunelerinin dayanımına olan etkisini nümerik ve deneysel olarak incelemiştir. Dolgu yoğunluğunun artması ile birlikte çekme dayanımının da arttığ edilmiştir. Tatlı ve arkadaşları [11] çalışmalarında kendi tasarlayıp ürettikleri üç boyutlu bir yazıcıda farklı dolgu geometrilerinin çekme eğilme ve Charpy darbe mukavemetine etkisini araştırmışlardır. Izgara geometrisinin maksimum çekme kuvvetine, geoid dolgunun maksimum eğilme dayanımına sahip olduğu tespit edilirken darbe yüküne karşı kayda değer bir etkisi olmadığg tespit edilmiştir. Akhoundi ve arkadaşları [12] üç boyutlu yazıcı ile üretilmiş farklı dolgu desenlerinin çekme ve eğilme dayanımına olan etkisini deneysel olarak incelemiştir.

Üç boyutlu yazıcılar ile üretilen numunelerin literatürde karşılaşılan bir diğer önemli testi ise basma testi olarak karşımıza çıkmaktadır. Haldar ve arkadaşları [13] PLA malzemeden üretilmiş 3D baskılı oluklu çekirdek tasarımına sahip sandviç yapıların sıkıştırma davranışı deneysel olarak incelemiştir. Solmaz ve arkadaşları [14] petek hücrelerinin üretiminde üç boyutlu yazıcı ile üretilen PLA ve ABS kullanılan altıgen yapılı sandviç yapıların basma dayanımlarını deneysel olarak incelemiştir. Farklı hücre boyutu ve farklı hücre yüksekliğine sahip yapılar testlerde kullanılmıştır. Maksimum dayanım $7 \mathrm{~mm}$ hücre boyutu ve $25 \mathrm{~mm}$ hücre yüksekliğinde elde edilmiştir. Chacon ve arkadaşları [15] eklemeli imalat yöntemi ile PLA malzemeden üretilen yapılar için, farklı üretim parametrelerinin mekanik özelliklere olan etkisi deneysel olarak incelenmiştir. Mekanik özelliklerin belirlenmesinde çekme ve üç nokta eğilme testleri uygulanmıştır. Katman katman üretim nedeniyle, 3 boyutlu yazdırılan yapıların anizotropik davranış sergilediği tespit edilmiştir. Ayrıca, dikey yönlendirme için katman kalınlığı arttıkça mekanik özelliklerin iyileştiği ve ilerleme hızı arttıkça azaldığ 1 tespit edilmiştir.

Bu çalışmada; Ultimaker 2 Extended 3 boyutlu yazıcıda ABS ve PLA malzeme ile farklı dolgu desenleri, farklı nozul ve tabla sicaklıkları kullanılarak eğme test numuneleri üretilmiştir. Dolgu deseninin, nozul ve tabla sicaklıklarının mekanik özellikler üzerindeki etkileri araştırılmıştır. Üretilen numunelerin kütleleri ölçülmüş ve üretilen numunelere eğme testi yapılmıştır. Eğme testleri sonucunda kuvvet-sehim eğrileri elde edilmiş ve farklı tasarım parametreleri için eğilme dayımları kıyaslanmıştır.

\section{MATERYAL VE METOT}

Çalışma kapsamında kullanılan 3 boyutlu yazıcı ve üretilen test numunelerinin mekanik özelliklerini belirlemede Kahramanmaraş Sütçü İmam Üniversitesi Makine Mühendisliği Bölümü ve Kahramanmaraş Sütçü İmam Üniversitesi ÜSKİM imkânları kullanılmıştır. Test numunelerinin üretiminde "Ultimaker 2 Extended" [16-17] 3B yazıcı kullanılmıştır (Şekil 1).

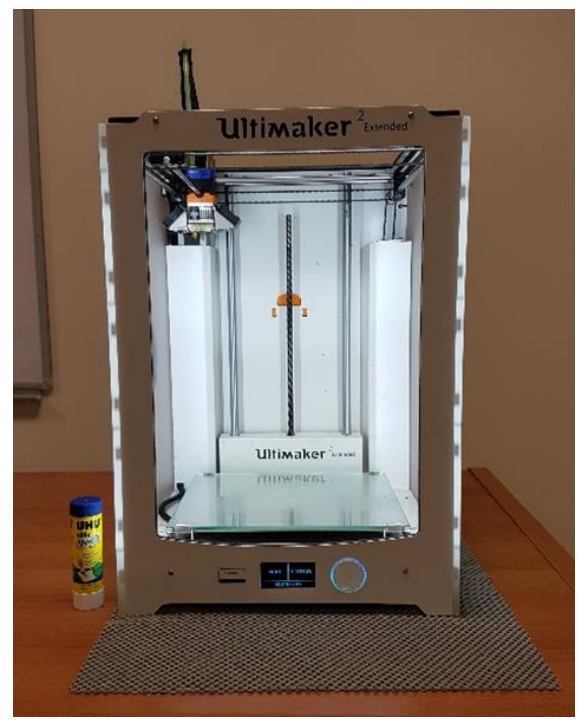

Şekil 1. Test numunelerinin üretiminde kullanılan Ultimaker 2 Extended 3B yazıcı 
3 Boyutlu Yazıcı ile Farklı Yazdırma Parametreleri Kullanılarak Üretilen Ĕgme Test Numunelerinin Mekanik Özelliklerinin İncelenmesi

Eğme test numunelerinin boyutlandırılmasında ASTM D790-17 standard1 [18] kullanılmıştır. Belirtilen standart ölçülerindeki eğme test numunesi 3 boyutlu olarak bilgisayar ortamında SolidWorks CAD yazılımı kullanılarak tasarlanmıştır.

\subsection{Farklı Nozul ve Tabla Sıcaklıkları Kullanılarak Yapılan Çalışmalar}

Kullanılan filament (ABS filament ve PLA filament), yazdirma nozul ve tabla sicaklıkları değiştirilerek ABS malzemede 5 farklı nozul sicaklığı $\left(80{ }^{\circ} \mathrm{C}\right.$ sabit tabla sicaklığında; $260{ }^{\circ} \mathrm{C}$, $250{ }^{\circ} \mathrm{C}, 240{ }^{\circ} \mathrm{C}, 230{ }^{\circ} \mathrm{C}, 220{ }^{\circ} \mathrm{C}$ ) ve 6 farkl tabla sicaklığı $\left(260{ }^{\circ} \mathrm{C}\right.$ sabit nozul sicaklığında; $80{ }^{\circ} \mathrm{C}$, $\left.70{ }^{\circ} \mathrm{C}, \quad 60{ }^{\circ} \mathrm{C}, \quad 50{ }^{\circ} \mathrm{C}, 40{ }^{\circ} \mathrm{C}, \quad 30{ }^{\circ} \mathrm{C}\right)$, PLA malzemede ise 6 farklı nozul sıcaklığı $\left(60{ }^{\circ} \mathrm{C}\right.$ sabit tabla sicaklığında; $240{ }^{\circ} \mathrm{C}, 230{ }^{\circ} \mathrm{C}, 220{ }^{\circ} \mathrm{C}$, $210{ }^{\circ} \mathrm{C}, 200{ }^{\circ} \mathrm{C}, 190{ }^{\circ} \mathrm{C}$ ) ve 4 farklı tabla sicaklığ $\left(240{ }^{\circ} \mathrm{C}\right.$ sabit nozul sicaklığında; $60{ }^{\circ} \mathrm{C}, 50{ }^{\circ} \mathrm{C}$, $40{ }^{\circ} \mathrm{C}, 30{ }^{\circ} \mathrm{C}$ ) kullanılarak eğme test numuneleri üretilmiştir. Ultimaker ABS malzeme ürün etiketinde belirtilen sicaklık aralığ $225-260^{\circ} \mathrm{C}$, Ultimaker PLA malzeme ürün etiketinde belirtilen sıcaklık aralığ $195-240^{\circ} \mathrm{C}^{\prime}$ dir. Her farklı parametre için dörder adet olacak şekilde, ABS malzeme ile 40 adet ve PLA malzeme ile 36 adet test numunesi üretilmiştir. 3 boyutlu yazıcıda farklı nozul ve tabla sicaklıklarında ABS ve PLA malzeme kullanılarak üretilen eğme test numunelerinin mekanik özellikleri karşılaştırılmıştır.

SolidWorks CAD yazılımı ile 3 boyutlu olarak tasarımı yapılan eğme test numunesinin Gkodlarının oluşturulmasında Ultimaker markasının kendi yazılımı olan Cura CAM yazılımı kullanılmıştır. Tasarımın yazıcı tablası üzerindeki konumu, açısı vb. ayarlar yapıldıktan sonra Çizelge 1'de belirtilen parametreler seçilerek tasarımın G-kodları oluşturulmuştur. Oluşturulan G-kodları SD kart yardımıyla 3 boyutlu yazıcıya aktarılmıştır.
ABS malzeme ile eğme test numunesi üretiminde öncelikle 3 boyutlu yazıcıda yazdırma tablasının manuel olarak kalibrasyonu yapılmıştır. 3 boyutlu yazıcıya Ultimaker marka ABS malzeme [19-20] takılmıştır. 3 boyutlu yazıcının yazdırma tabla ve nozul sıcaklığı yukarıda belirtilen değerlere ayarlanmıştır.

Çizelge 1. Farklı nozul ve tabla sıcaklığı çalışmaları için Cura CAM yazılımında seçilen parametreler

\begin{tabular}{|l|l|}
\hline Yazıcı & $\begin{array}{l}\text { Ultimaker 2 extended with } \\
\text { olsson block }\end{array}$ \\
\hline Malzeme & $\begin{array}{l}\text { Ultimaker ABS veya } \\
\text { ultimaker PLA }\end{array}$ \\
\hline Nozul çapı & $0,4 \mathrm{~mm}$ \\
\hline Katman kalınlığı & $0,2 \mathrm{~mm}$ \\
\hline Duvar kalınlığı & $0 \mathrm{~mm}$ \\
\hline Üst/Alt kalınlığı & $0 \mathrm{~mm}$ \\
\hline Dolgu yoğunluğu & $\% 100$ \\
\hline Dolgu deseni & Lines $0^{\circ}($ Şekil 2) \\
\hline Yazdırma hızı & $60 \mathrm{~mm} / \mathrm{s}$ \\
\hline Boşta gezme hızı & $120 \mathrm{~mm} / \mathrm{s}$ \\
\hline
\end{tabular}

PLA malzeme ile eğme test numunesi üretiminde öncelikle 3 boyutlu yazıcıda yazdırma tablasının manuel olarak kalibrasyonu yapılmıştır. 3 boyutlu yazıcıya Ultimaker marka PLA malzeme [21-22] takılmıştır. 3 boyutlu yazıcının yazdırma tabla ve nozul sıcaklığı yukarıda belirtilen değerlere ayarlanmıştır.

Üretim işlemini başlatmadan önce, üretim sırasında numunenin ilk katmanının cam yazdırma tablasına daha iyi yapışmasını sağlamak için yazdırma tablası üzerine ince bir film tabakası kalınlığından yapıştırıcı (Uhu Stic Magic Blue) sürülmüştür. 

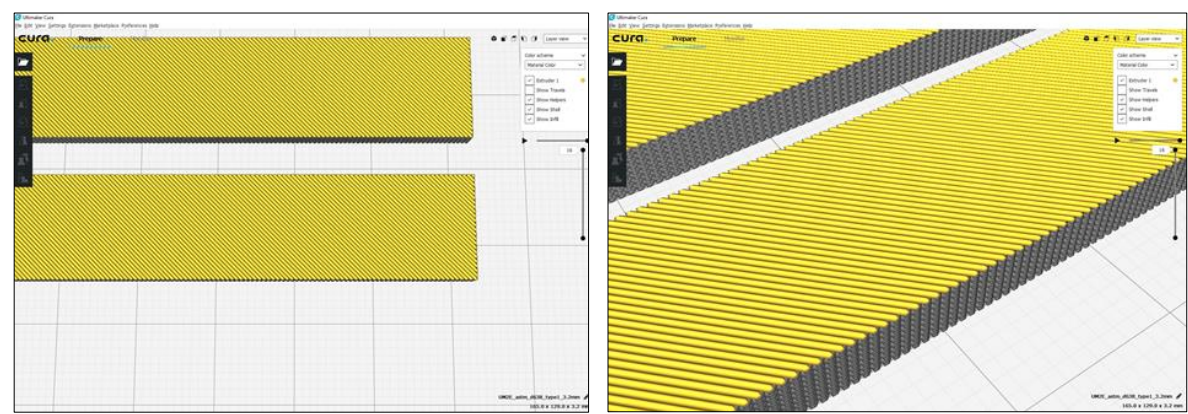

Şekil 2. Cura CAM programında seçilen Lines $0^{\circ}$ dolgu deseni görüntüleri

\subsection{Farklı Dolgu Desenleri Kullanılarak Yapılan Çalışmalar}

5 farklı dolgu deseni (Lines $0^{\circ}$-Lines $90^{\circ}$ Connect -Lines $180^{\circ}$-Concentric-Zig Zag) kullanılarak her parametre için dörder adet olacak şekilde, 20 adet ABS ve 20 adet PLA malzeme ile toplam 40 adet test numunesi üretilmiştir. 3 boyutlu yazıcıda aynı parametrelerde ABS ve PLA malzeme kullanılarak üretilen numunelerin mekanik özellikleri karşılaştırılmıştır.

SolidWorks CAD yazılımı ile 3 boyutlu olarak tasarımı yapılan eğme numunesinin G-kodlarının oluşturulmasında Ultimaker markasının kendi yazılımı olan Cura CAM yazılımı kullanılmıştır. Tasarımın yazıcı tablası üzerindeki konumu, açısı vb. ayarlar yapıldıktan sonra Çizelge 2'de belirtilen parametreler seçilerek tasarımın Gkodları oluşturulmuştur. G-kodlarının oluşturulmasında belirtilen parametrelerden sadece dolgu deseni (Lines $0^{\circ}$-Lines $90^{\circ}$ Connect-Lines $180^{\circ}$-Concentric-Zig Zag) değiştirilerek farklı Gkodları oluşturulmuştur. Cura CAM programında seçilen dolgu deseni görüntüleri Şekil 3'de gösterilmiştir. Oluşturulan G-kodları SD kart yardımıyla 3 boyutlu yazıcıya aktarılmıştır.

Ultimaker 2 Extended 3 boyutlu yazıcıda öncelikle baskı tablasının manuel olarak kalibrasyonu yapılmıştır. 3 boyutlu yazıcıya Ultimaker marka ABS malzeme [19-20] veya Ultimaker marka PLA malzeme [21-22] takılmıştır. Tüm eğme numuneleri bu malzemeler kullanılarak üretilmiştir. Ultimaker 2 Extended 3 boyutlu yazıcının baskı tablasının sıcaklığı ABS malzeme kullanıldığında $\quad 80^{\circ} \mathrm{C}$ 'ye, PLA malzeme kullanıldığında ise $60{ }^{\circ} \mathrm{C}$ 'ye (Ultimaker $\mathrm{ABS}$ ve PLA malzemelerin ürün etiketlerinde belirtilen değere) ayarlanmıştır. ABS malzeme kullanılırken 3 boyutlu yazıcının nozul sicaklığ $260{ }^{\circ} C^{\prime}$ ye (225-260 ${ }^{\circ} \mathrm{C}$ Ultimaker $\mathrm{ABS}$ ürün etiketinde belirtilen sıcaklık aralığı) ayarlanmıştır. PLA malzeme kullanılırken 3 boyutlu yazıcının nozul sıcaklığ1 $240{ }^{\circ} \mathrm{C}^{\prime}$ ye $\left(195-240{ }^{\circ} \mathrm{C}\right.$ Ultimaker PLA ürün etiketinde belirtilen sicaklık aralığı) ayarlanmıştır. Üretim işlemini başlatmadan önce, üretim sırasında numunenin ilk katmanının cam yazdırma tablasına daha iyi yapışmasını sağlamak için yazdırma tablası üzerine ince bir film tabakası kalınlığında stick yapıştırıcı (Uhu Stic Magic Blue) sürülmüştür. ABS ve PLA malzemeler kullanılarak üretilen numunelerin bir kısmı Şekil 3'de gösterilmiştir.

Çizelge 2. Farklı dolgu deseni çalışmaları için Cura CAM yazılımında seçilen parametreler

\begin{tabular}{|l|l|}
\hline Yazıcı & $\begin{array}{l}\text { Ultimaker 2 Extended with } \\
\text { olsson block }\end{array}$ \\
\hline Malzeme & $\begin{array}{l}\text { Ultimaker ABS veya ultimaker } \\
\text { PLA }\end{array}$ \\
\hline Nozul çapı & $0,4 \mathrm{~mm}$ \\
\hline Katman kalınlığ1 & $0,2 \mathrm{~mm}$ \\
\hline Duvar kalınlığ1 & $0 \mathrm{~mm}$ \\
\hline Üst/alt kalınlığ1 & $0 \mathrm{~mm}$ \\
\hline Dolgu yoğunluğu & $\% 100$ \\
\hline & $\begin{array}{l}\text { Lines } 0^{\circ} \text {-Lines } 90^{\circ} \text { Connect- } \\
\text { Lines } 180^{\circ} \text {-Concentric-Zig } \\
\text { Zag (5 farklı dolgu deseni } \\
\text { kullanılarak test numuneleri } \\
\text { üretilmiştir) }\end{array}$ \\
\hline Dolgu deseni & $60 \mathrm{~mm} / \mathrm{s}$ \\
\hline Yazdırma hızı & $120 \mathrm{~mm} / \mathrm{s}$ \\
\hline Boşta gezme hızı &
\end{tabular}


3 Boyutlu Yazıcı ile Farklı Yazdırma Parametreleri Kullanılarak Üretilen Ĕgme Test Numunelerinin Mekanik Özelliklerinin İncelenmesi
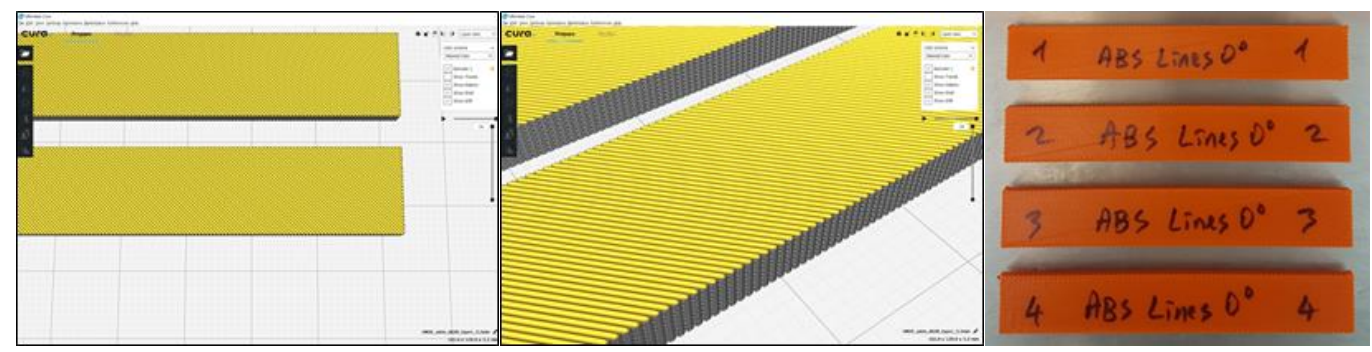

a) Lines $0^{\circ}$ dolgu deseni görüntüleri ve üretilmiș örnek numuneler

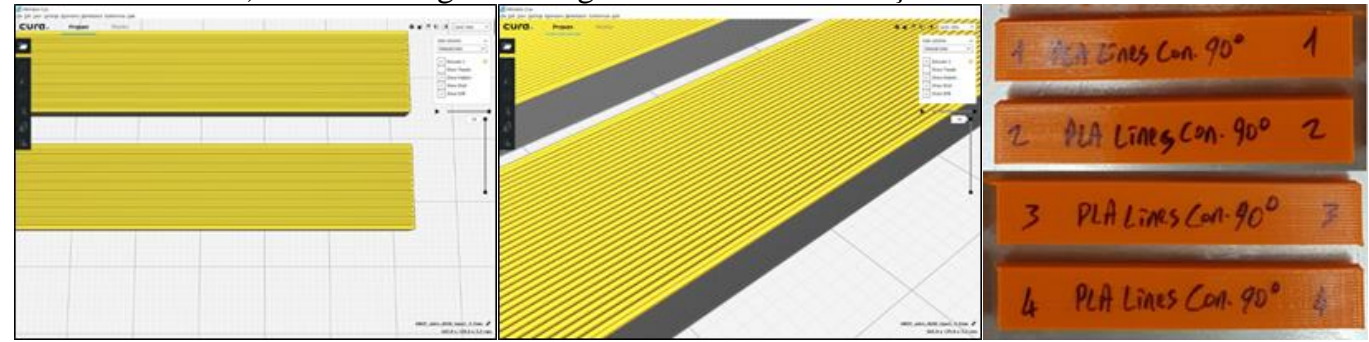

b) Lines $90^{\circ}$ Connect dolgu deseni görüntüleri ve üretilmiş örnek numuneler

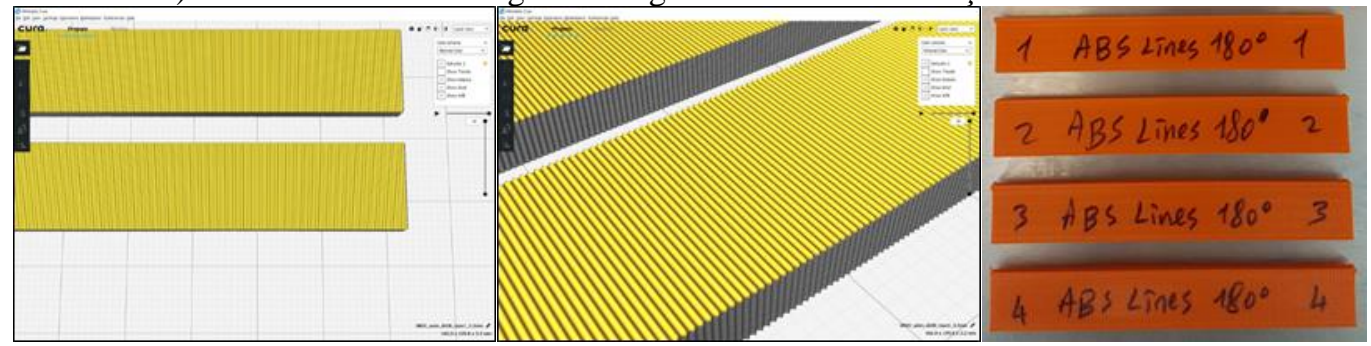

c) Lines $180^{\circ}$ dolgu deseni görüntüleri ve üretilmiş örnek numuneler

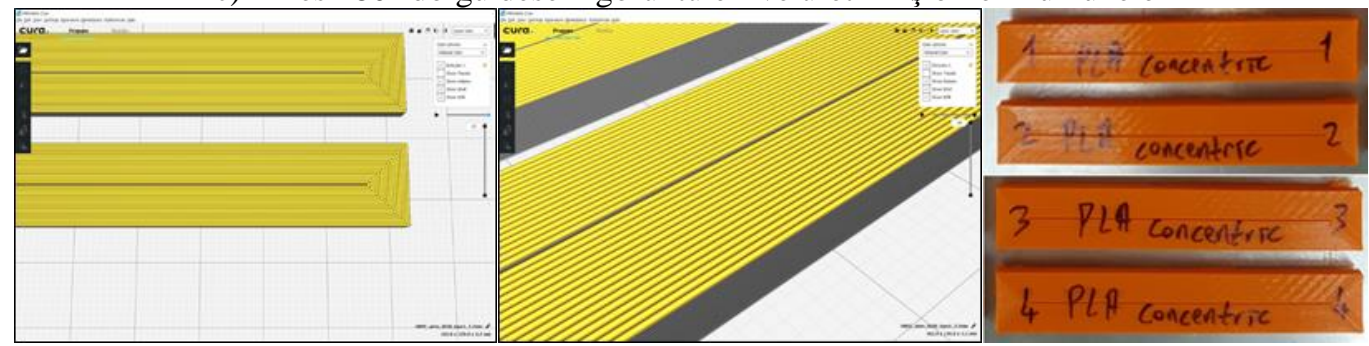

d) Concentric dolgu deseni görüntüleri ve üretilmiş örnek numuneler

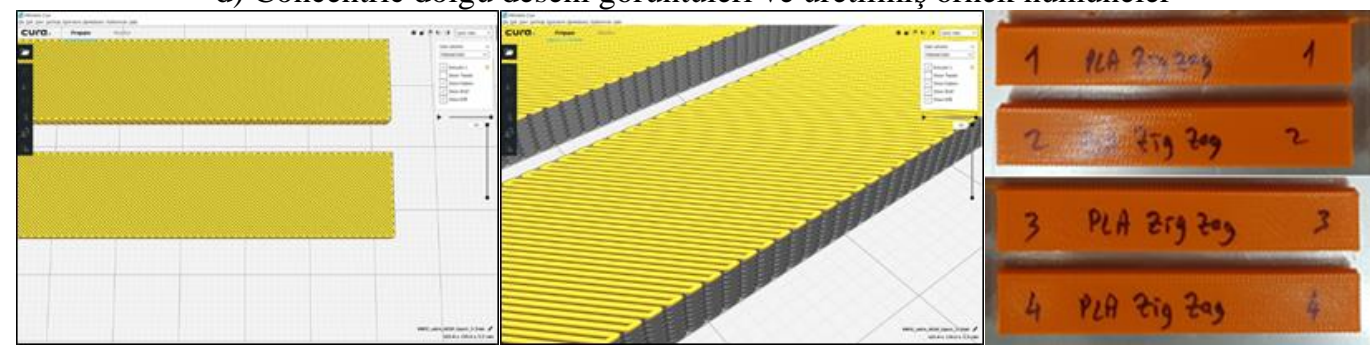

e) Zig Zag dolgu deseni görüntüleri ve üretilmiş örnek numuneler

Şekil 3. Cura CAM programında seçilen dolgu deseni görüntüleri ve üretilmiş örnek numuneler 


\section{BULGULAR VE TARTIŞMA}

Bu çalışmada; Ultimaker 2 Extended 3 boyutlu yazıcıda ABS ve PLA malzeme ile farklı dolgu desenleri, farklı nozul ve tabla sicaklıkları kullanılarak eğme test numuneleri üretilmiştir. Dolgu deseninin, nozul ve tabla sicaklıklarının mekanik özellikler üzerindeki etkileri araştırılmıştır.

\subsection{Farklı Nozul ve Tabla Sicaklıkları Kullanılarak Yapılan Çalışmalardan Elde Edilen Veriler}

Farklı tabla sıcaklıkları kullanılarak ABS ve PLA malzeme ile üretilen numunelerin kütle değerleri Çizelge 3'de verilmiştir. Çizelge 3 incelendiğinde farklı tabla sıcaklıkları kullanılarak ABS ve PLA malzeme ile üretilen numunelerin kütlesinde kayda değer bir değişiklik olmadığı görülmektedir. Çizelge 3'de görülen küçük kütle farklılıklarının numuneler üzerindeki yapıştırıcı kalıntıları, üretim sırasındaki buharlaşma miktarı gibi etkenlerden kaynaklandığı düşünülmektedir.

Çizelge 3. Farklı tabla sıcaklıkları kullanılarak üretilen test numunelerinin kütle değerleri

\begin{tabular}{|c|c|c|c|}
\hline \multirow{2}{*}{$\begin{array}{c}\text { Filament } \\
\text { türü }\end{array}$} & $\begin{array}{c}\text { Nozul } \\
\text { sicaklığ1 } \\
\left(\mathrm{C}^{\circ}\right)\end{array}$ & $\begin{array}{c}\text { Tabla } \\
\text { sicaklı̆̆1 } \\
\left(\mathrm{C}^{\circ}\right)\end{array}$ & $\begin{array}{c}\text { Ölçülen } \\
\text { değerler }\end{array}$ \\
\cline { 4 - 4 } & & $\begin{array}{c}\text { Ortalama } \\
\text { kütle }(\mathrm{g})\end{array}$ \\
\hline ABS & 260 & 80 & 3,71 \\
\hline ABS & 260 & 70 & 3,70 \\
\hline ABS & 260 & 60 & 3,66 \\
\hline ABS & 260 & 50 & 3,70 \\
\hline ABS & 260 & 40 & 3,48 \\
\hline ABS & 260 & 30 & 3,53 \\
\hline PLA & 240 & 60 & 3,85 \\
\hline PLA & 240 & 50 & 3,82 \\
\hline PLA & 240 & 40 & 3,88 \\
\hline PLA & 240 & 30 & 3,91 \\
\hline
\end{tabular}

Farklı nozul ve tabla sıcaklıkları kullanılarak ABS ve PLA malzeme ile üretilen numunelerin kütle değerleri Çizelge 3 ve Çizelge 4'de verilmiştir. Bu sonuçlar incelendiğinde Cura CAM programından alınan filament boyu verilerinin tüm numuneler için aynı olduğu görülmektedir. Bu da programda hesaplanan yazdırma için gerekli olan malzeme miktarının her malzeme için tüm renklerde aynı olması gerektiği anlamına gelmektedir.

Çizelge 4. Farklı nozul sıcaklıkları kullanılarak üretilen test numunelerinin kütle değerleri

\begin{tabular}{|c|c|c|c|}
\hline \multirow{2}{*}{$\begin{array}{c}\text { Filament } \\
\text { türü }\end{array}$} & $\begin{array}{c}\text { Nozul } \\
\text { sicaklığ1 } \\
\left(\mathrm{C}^{\mathrm{o}}\right)\end{array}$ & $\begin{array}{c}\text { Tabla } \\
\text { sicaklığ } \\
\left(\mathrm{C}^{\circ}\right)\end{array}$ & $\begin{array}{c}\text { Ölçülen } \\
\text { değerler }\end{array}$ \\
\cline { 4 - 4 } & $\begin{array}{c}\text { Ortalama } \\
\text { kütle }(\mathrm{g})\end{array}$ \\
\hline ABS & 260 & 80 & 3,71 \\
\hline ABS & 250 & 80 & 3,51 \\
\hline ABS & 240 & 80 & 3,70 \\
\hline ABS & 230 & 80 & 3,54 \\
\hline ABS & 220 & 80 & 3,76 \\
\hline PLA & 240 & 60 & 3,85 \\
\hline PLA & 230 & 60 & 3,83 \\
\hline PLA & 220 & 60 & 3,74 \\
\hline PLA & 210 & 60 & 3,40 \\
\hline PLA & 200 & 60 & 3,39 \\
\hline PLA & 190 & 60 & 2,80 \\
\hline
\end{tabular}

Farklı nozul sıcaklıkları kullanılarak ABS ve PLA malzeme ile üretilen numunelerin kütle değerleri Çizelge 4'de verilmiştir. Çizelge 4 incelendiğinde farklı tabla sıcaklıkları kullanılarak ABS malzeme ile üretilen numunelerin kütlesinde kayda değer bir değişiklik olmadığı görülmektedir. Fakat nozul sıcaklığının azalmasıyla PLA malzeme ile üretilen numunelerin kütlelerinin de benzer şekilde azaldığı görülmektedir. Bunun nedeni olarak; nozul sıcaklığının azalmasıyla PLA filamentin nozul içerisinde yeteri kadar erimeye fırsat bulamadan ittirilmesi gerektiğinden, ABS filamente göre daha sert ve pürüzsüz bir yüzeye sahip olan PLA filamentin, filament besleme motorunda bir miktar kaydırmaya (patinaj) neden olduğu söylenebilir. $\mathrm{Bu}$ da sonuç olarak üretilen PLA eğme test numunelerinde kütle kaybı olarak karşımıza çıkmaktadır.

Şekil 4'de her iki malzeme ile farklı nozul ve tabla sıcaklıklarında üretilen numunelerin kuvvet-sehim eğrileri verilmiştir. Şekil 4 incelendiğinde, farklı 
3 Boyutlu Yazıcı ile Farklı Yazdırma Parametreleri Kullanılarak Üretilen Eğme Test Numunelerinin Mekanik Özelliklerinin İncelenmesi

nozul ve tabla sicakliklarında ABS malzeme kullanılarak üretilen numunelerin kuvvet-sehim eğrilerinin birbirlerine çok yakın olduğu söylenebilir. Şekil 4'de ABS malzeme kuvvetsehim eğrilerinde görülen kü̧̧ük farklılıkların numuneler üzerindeki yapıştırıcı kalıntıları, üretim sırasındaki buharlaşma miktarı gibi etkenlerden kaynaklandığı düşünülmektedir. Benzer sekilde Şekil $4 c$ incelendiğinde, farklı tabla sicaklıkları kullanılarak PLA malzeme ile üretilen numunelerin kuvvet-sehim eğrilerinin birbiriyle çakışı olduğu görülmektedir. Fakat farklı nozul sıcaklıkları kullanılarak PLA malzeme ile üretilen numunelerin kuvvet-sehim eğrileri (Şekil 4d)

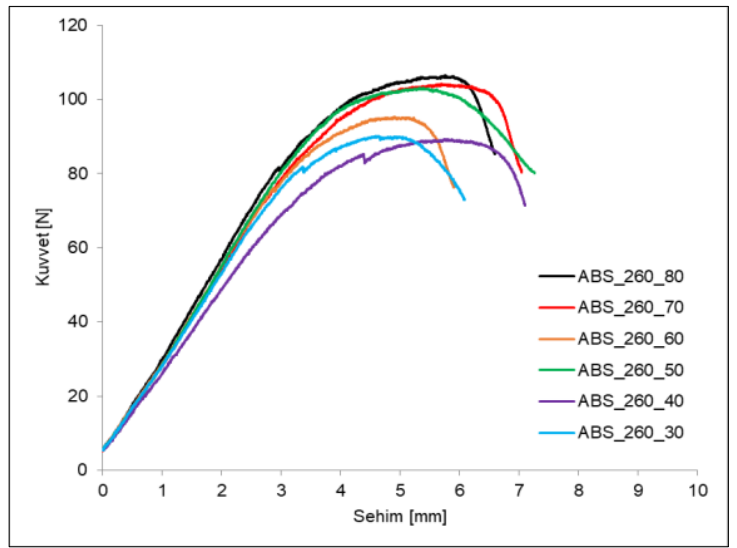

a) ABS malzeme tabla sıcaklığı değişimi

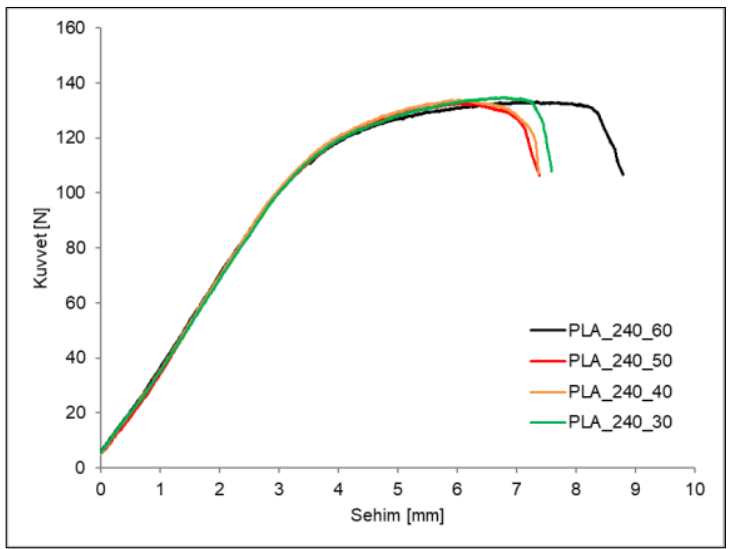

c) PLA malzeme tabla sıcaklığı değişimi incelendiğinde, nozul sicaklığının azalmasıyla eğilme dayanımlarının azaldığı ve sehim miktarlarının ise arttığı görülmektedir.

ABS ve PLA malzemeler ile üretilen test numuneleri kendi aralarında kıyaslandığında, PLA malzeme ile üretilen numunelerin eğilme dayanımlarının genel olarak ABS malzeme ile üretilen numunelerden daha yüksek olduğu tespit edilmiștir. Literatür incelendiğinde benzer sonuçların Rodríguez-Panes ve arkadaşları [7] yapmış oldukları çalışmada da görmek mümkündür.

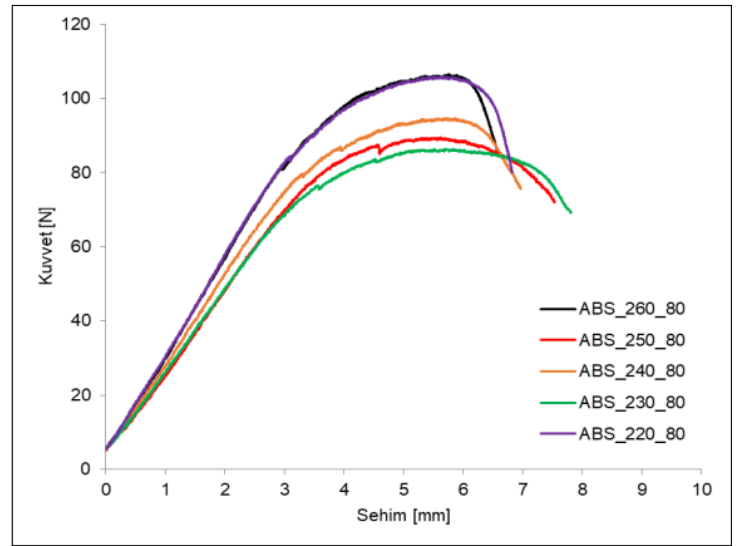

b) ABS malzeme nozul sıcaklığı değişimi

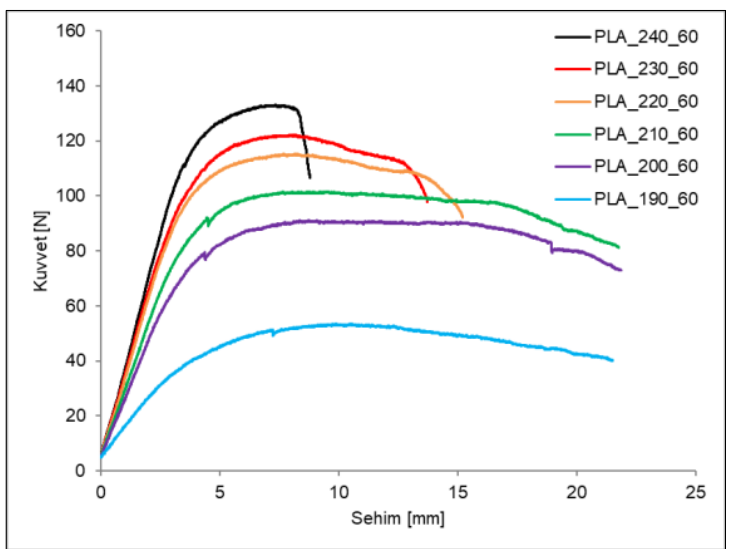

d) PLA malzeme nozul sıcaklığı değişimi

Şekil 4. Farklı tabla ve nozul sıcaklıkları kullanılarak üretilen eğme test numunelerinin kuvvet-sehim eğrileri 


\subsection{Farklı Dolgu Desenleri Kullanılarak Yapılan Çalışmalardan Elde Edilen Veriler}

Farklı dolgu desenleri kullanılarak ABS ve PLA malzemelerle üretilen numunelerin kütle değerleri Çizelge 5'de verilmiştir. Çizelge 5 incelendiğinde farklı dolgu desenleri kullanılarak ABS ve PLA filamentlerle üretilen numunelerin kütlelerinde dolgu deseninin değişimine bağlı olarak kayda değer bir değişiklik olmadığı görülmektedir. Çizelge 5'de görülen küçük kütle farklılıklarının numuneler üzerindeki yapıştırıcı kalıntıları, üretim sırasındaki buharlaşma miktarı gibi etkenlerden kaynaklandığı söylenebilir.

Şekil 5'de her iki malzeme ile farklı dolgu desenleri kullanılarak üretilen numunelerin kuvvetsehim eğrileri verilmiştir. Şekil 5a incelendiğinde, Lines $180^{\circ}$ dolgu deseni kullanılarak ABS malzeme ile üretilen numunelerin gevrek malzeme gibi bir davranış sergilediği, akma olmadan malzemenin koptuğu görülmektedir. ABS malzeme ile Lines $90^{\circ}$ Connect ve Concentric dolgu desenleriyle üretilen numunelerin en yüksek eğilme dayanımına ve en yüksek sehim miktarına sahip dolgu tipleri olduğu ve bu dolgu desenlerine sahip numunelerin kuvvet-sehim eğrilerinin birbirlerine çok yakın olduğu söylenebilir. ABS malzeme ile Lines $0^{\circ}$ ve Zig Zag dolgu desenleriyle üretilen numunelerin kuvvet-sehim eğrilerinin neredeyse birbiriyle çakışık olduğu görülmektedir.

Şekil $5 \mathrm{~b}$ incelendiğinde, Lines $180^{\circ}$ dolgu deseni kullanılarak PLA malzeme ile üretilen numunelerin gevrek malzeme gibi bir davranış sergilediği görülmektedir. PLA malzeme ile Lines $90^{\circ}$ Connect ve Concentric dolgu desenleriyle üretilen numunelerin en yüksek eğilme dayanımına sahip dolgu tipleri olduğu ve bu dolgu desenlerine sahip numunelerin kuvvet-sehim eğrilerinin birbirlerine çok yakın olduğu söylenebilir. PLA malzeme ile Lines $0^{\circ}$ ve $\mathrm{Zig} \mathrm{Zag}$ dolgu desenleriyle üretilen numunelerin kuvvet-sehim eğrilerinin birbirlerine çok yakın olduğu ve bu dolgu desenlerinin en yüksek sehim miktarına sahip desenler olduğu görülmektedir. Dezaki ve arkadaşları [23] ve Tatlı ve arkadaşları [11] gerçekleştirdikleri çalışmalarda dolgu deseninin mekanik özellikler üzerine olan etkilerini incelemişlerdir. Elde ettikleri sonuçlar incelediğinde, bu çalışmada elde edilen sonuçların literatür ile uyumlu olduğu tespit edilmiştir.

Çizelge 5. Farklı dolgu desenleri kullanılarak üretilen test numunelerinin kütle değerleri

\begin{tabular}{|c|c|c|c|c|}
\hline \multirow{2}{*}{$\begin{array}{c}\text { Filament } \\
\text { türü }\end{array}$} & Dolgu deseni & $\begin{array}{c}\text { Nozul } \\
\text { sicaklığ } \\
\left(\mathrm{C}^{\circ}\right)\end{array}$ & $\begin{array}{c}\text { Tabla } \\
\text { sicaklığ } \\
\left(\mathrm{C}^{\circ}\right)\end{array}$ & $\begin{array}{c}\text { Ölçülen } \\
\text { değerler }\end{array}$ \\
\cline { 5 - 6 } & $\begin{array}{c}\text { Ortalama } \\
\text { kütle (g) }\end{array}$ \\
\hline ABS & Lines $0^{\circ}$ & 260 & 80 & 3,71 \\
\hline ABS & $\begin{array}{c}\text { Lines } 90^{\circ} \\
\text { Connect }\end{array}$ & 260 & 80 & 3,75 \\
\hline ABS & Lines $180^{\circ}$ & 260 & 80 & 3,71 \\
\hline ABS & Concentric & 260 & 80 & 3,69 \\
\hline PLA & Zig Zag & 260 & 80 & 3,69 \\
\hline PLA & $\begin{array}{c}\text { Lines } 90^{\circ} \\
\text { Connect }\end{array}$ & 240 & 60 & 3,85 \\
\hline PLA & Lines $180^{\circ}$ & 240 & 60 & 3,92 \\
\hline PLA & Concentric & 240 & 60 & 3,82 \\
\hline PLA & Zig Zag & 240 & 60 & 3,93 \\
\hline
\end{tabular}

ABS ve PLA malzemeler ile üretilen ürünlerin gerilme-şekil değiştirme eğrileri kendi aralarında kıyaslandığında, PLA malzeme ile üretilen numunelerin genel olarak eğilme dayanımlarının ABS malzemeye göre daha yüksek, sehim miktarlarının ise ABS malzemeye göre daha düşük olduğu tespit edilmiştir. Benzer sonuçlar literatürde birçok çalışmada görülmektedir $[1,2,7]$. 


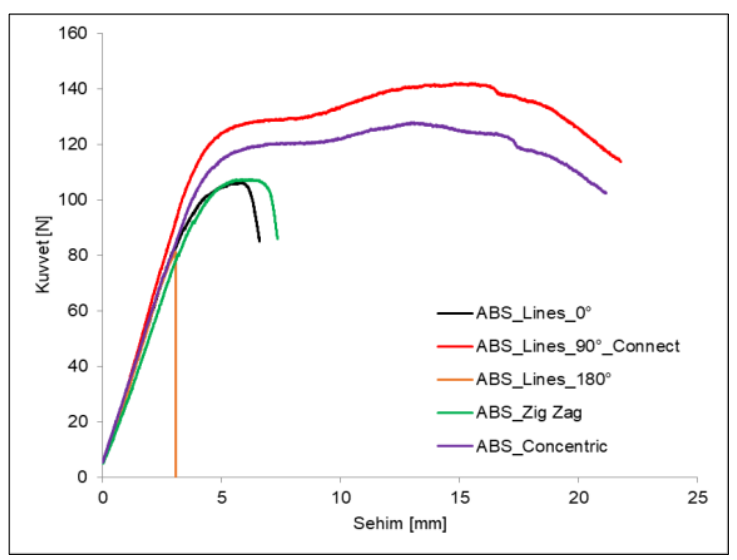

a) ABS malzeme dolgu deseni değişimi

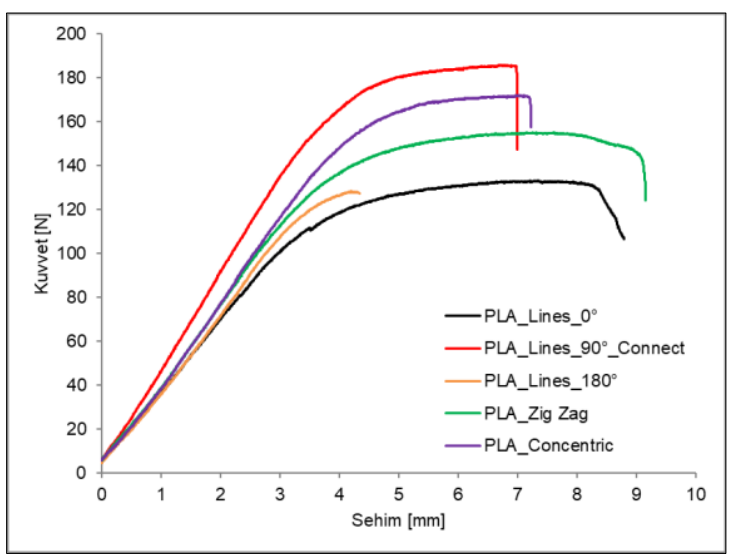

b) PLA malzeme dolgu deseni değişimi

Şekil 5. Farklı dolgu desenleri kullanılarak üretilen eğme test numunelerinin kuvvet-sehim eğrileri

\section{SONUÇLAR}

$\mathrm{Bu}$ çalışmada, eklemeli imalat yöntemi ile üretilmiş farklı üretim parametrelerine sahip eğme deney numunelerinin eğilme dayanımları deneysel olarak incelenmiştir. Nozul, tabla sıcaklıkları ve dolgu desenleri farklılık gösteren PLA ve ABS malzemeden üretilmiş eğme numuneleri deneylerde kullanılmıştır. Her bir numune üç nokta eğme deneyine tabi tutulmuş ve kuvvet-sehim eğrileri elde edilerek, her bir numunenin eğilme dayanımları test edilmiştir. Gerçekleştirilen deneyler sonucunda elde edilen sonuçlar aşağıdaki gibi özetlenebilir.

- ABS malzeme ile üretilen deney numunelerinde nozul ve tabla sicaklığının değişimi ile eğilme dayanımları üzerinde en fazla \%15'lik bir değişim olduğu gözlemlenmiştir. Bu nedenle ABS malzemesi için nozul ve tabla sıcaklıkları değişimin eğilme dayanıma çok fazla etki etmediği tespit edilmiştir.

- PLA malzeme ile üretilen deney numunelerinde tabla sıcaklığının değişimi eğilme dayanımını hemen hemen hiç etkimez iken, nozul sıcaklığının azalması ile eğilme dayanımının hızlı bir şekilde düştüğü ancak malzemenin daha bir sünek yapıya kavuştuğu belirlenmiştir.
- Line_90 $90^{\circ}$ Connect ve Concentric dolgu desenlerine sahip deney numunelerinin en yüksek eğilme dayanımlarına sahip olduğu, Lines_180 dolgu desenine sahip numunelerin en düşük eğilme dayanıma sahip olduğu tespit edilmiştir.

$\mathrm{Bu}$ çalışmadan sonra, benzer üretim parameterleri ile üretilecek olan, çekme, basma veya darbe numunelerinin dayanımları incelenerek, üç boyutlu yazdırma parametrelerinin malzemenin farklı mekanik özelliklerine olan etkisi incelenecektir.

Ayrıca elde edilen eğriler sonlu elemanlar analiz programlarına tanımlanarak farklı geometriye sahip yapılar için yapısal analizler gerçekleştirilebilecektir.

\section{TEŞEKKÜR}

Bu çalışma; İnönü Üniversitesi Rektörlüğü Bilimsel Araştırma Projeleri Koordinasyon Birimi tarafindan FDK-2020-2351 nolu proje ile desteklenmiştir.

\section{KAYNAKLAR}

1. Ngo, T.D., Kashani, A., Imbalzano, G., Nguyen, K.T.Q., Hui, D., 2018. Additive Manufacturing (3D Printing): A Review of Materials, Methods, Applications and Challenges, Composites Part B, 143, 172-196. 
2. Popescu, D., Zapciu, A., Amza, C., Baciu, F., Marinescu, R., 2018. Process Parameters Influence Over the Mechanical Properties of Polymer Specimens: A Review. Polymer Testing, 69, 157-166.

3. Jayanth, N., Senthil, P., Prakash, C., 2018. Effect of Chemical Treatment on Tensile Strength and Surface Roughness of 3D-printed ABS Using the FDM Process. Virtual and Physical Prototyping, 13(3), 155-163.

4. Rajpurohit, S.R., Dave, H.K., 2019. Analysis of Tensile Strength of a Fused Filament Fabricated PLA Part Using an Open-source 3D Printer. The International Journal of Advanced Manufacturing Technology, 101, 1525-1536.

5. Uzun, M., Erdoğdu, Y.E., 2020. Eriyik Yığma Modellemesi ile Üretimde Takviyesiz ve Takviyeli PLA Kullanımının Mekanik Özelliklere Etkisinin Araştırılması. Iğdır Üniversitesi Fen Bilimleri Enstitüsü Dergisi, 10(4), 2800-2808.

6. Ando, M., Birosz, M., Jeganmohan, S., 2021. Surface Bonding of Additive Manufactured Parts from Multi-colored PLA Materials. Measurement, 169, 108583.

7. Rodríguez-Panes, A., Claver, J., Camacho, A.M., 2018. The Influence of Manufacturing Parameters on the Mechanical Behaviour of PLA and ABS Pieces Manufactured by FDM: A Comparative Analysis. Materials, 11(1333), $1-21$.

8. Tezel, T., Ozenc, M., Kovan, V., 2021. Impact Properties of 3D-printed Engineering Polymers. Materials Today Communications, 26, 102161.

9. Sood, A.K., Ohdar, R.K., Mahapatra, S.S., 2010. Parametric Appraisal of Mechanical Property of Fused Deposition Modelling Processed Parts. Materials and Design, 31, 287-295.

10.Liu, C.H., Chen, Y., Yang, S.Y., 2021, Quantification of Hyperelastic Material Parameters for a 3D-Printed Thermoplastic Elastomer with Different Infill Percentages. Materials Today Communications, 26, 101895.

11. Tatlı, O., Özgül, H.G., 2020. Üç Boyutlu Yazıc1 Tasarımı, İmalatı ve Dolgu Geometrisinin Mekanik Özelliklere Etkisi.
Icontech International Journal of Surveys. Engineering, Technology, 4, 1, 13-24.

12. Akhoundi, B., Behravesh, A.H., 2019. Effect of Filling Pattern on the Tensile and Flexural Mechanical Properties of FDM 3D Printed Products. Experimental Mechanics, 59, 883-897.

13. Haldar, A.K., Managuli, V., Munshi, R., Agarwal, R.S., Guan, Z.W., 2021. Compressive Behaviour of 3D Printed Sandwich Structures Based on Corrugated Core Design. Materials today communications, 26, 101725.

14. Solmaz, M.Y., Çelik, E., 2018. 3 Boyutlu Yazıcı Kullanılarak Üretilen Bal Peteği Sandviç Kompozitlerin Basma Yükü Altındaki Performanslarının Araştırılması. Fırat Üniv. Müh. Bil. Dergisi, 30, 1, 277 - 286.

15. Chacon, J.M., Caminero, M.A., Garcia-Plaza, E., Nunez, P.J., 2017. Additive Manufacturing of PLA Structures Using Fused Deposition Modelling: Effect of Process Parameters on Mechanical Properties and Their Optimal Selection. Materials and design, 124, 143 -157.

16. The Ultimaker 2 Extended Specifications, (n.d.). Erişim Adresi: https://support.ultimaker. com/hc/en-us/articles/360011987939-The-

Ultimaker-2-Extended-specifications (Erişim Tarihi: 06.02.2021).

17. The Ultimaker 2 Extended User Manual, (n.d.). Erişim Adresi: https://support.ultimaker.com/ hc/en-us/articles/360011987819-The-

Ultimaker-2-Extended-user-manual (Erişim Tarihi: 06.02.2021).

18. ASTM D790-17, Standard Test Methods for Flexural Properties of Unreinforced and Reinforced Plastics and Electrical Insulating Materials, ASTM International, West Conshohocken, PA, 2014, www.astm.org, https://doi.org/10.1520/D0790-17.

19. Ultimaker ABS SDS, (2017). Erişim Adresi: https://support.ultimaker.com/hc/enus/articles/360011962900-Ultimaker-ABSSDS (Erişim Tarihi: 15.02.2021).

20. Ultimaker ABS TDS, (2018). Erişim Adresi: https://support.ultimaker.com/hc/enus/articles/360012759139-Ultimaker-ABSTDS (Erişim Tarihi: 15.02.2021). 
3 Boyutlu Yazıcı ile Farklı Yazdırma Parametreleri Kullanılarak Üretilen Eğme Test Numunelerinin Mekanik Özelliklerinin İncelenmesi

21. Ultimaker PLA SDS, (2019). Erişim Adresi: https://support.ultimaker.com/hc/enus/articles/360012759359-Ultimaker-PLA-SDS (Erişism Tarihi: 15.02.2021).

22. Ultimaker PLA TDS, (2018). Erişim Adresi: https://support.ultimaker.com/hc/enus/articles/360011962720-Ultimaker-PLATDS (Erişim Tarihi: 15.02.2021).

23. Dezaki, M.L., Ariffin, M.K.A.M., 2020. The Effects of Combined Infill Patterns on Mechanical Properties in FDM Process, Polymers, 12, 1-20. 